\title{
NUMERICAL ANALYSIS OF FATIGUE DAMAGE ON SELECTED CONNECTION OF THE CRANE BRIDGE SUPPORT STRUCTURE
}

\author{
M. Krejsa*, P. Pařenica ${ }^{* *}$, P. Lehner ${ }^{* * *}$, J. Brožovský ${ }^{\dagger}$, V. Křivý ${ }^{\ddagger}$, J. Kozák
}

\begin{abstract}
The article deals with a numerical analysis of selected connection of diagonal of the steel truss structure supporting the crane track. The analysis focused on the prediction of fatigue damage of the most stressed members. The initial static analysis of the entire structure helped to determine the influence lines for the selected elements. The main goal of this article is numerical model of particular connection of diagonal. Numerical model uses the variable load amplitude obtained from probability analysis converted to the amplitude spectrum of static magnitudes like input parameters. The Rain Flow method from software ANSYS Workbench is used for fatigue analysis of numerical model. The critical parts in terms of fatigue and life expectancy are identifying by this approach.
\end{abstract}

Keywords: numerical modeling, fatigue, steel structure, crane bridge, FEM, rain flow, ANSYS

\section{Introduction}

Fatigue phenomenon is one of the main factors controlling the life of steel construction supporting crane bridge. Fatigue damage is caused by the accumulation of live load stress over a long time. The bearing structure is crucial for safety and reliability. Crossing frequencies leads to higher fatigue damage. Due to these it is highly relevant to develop methods for the calculation and assessment of the residual fatigue life and time-dependent analysis of the reliability of existing steel construction (Xiang et al., 2011 and Ye et al., 2014).

The initiation position of a fatigue crack is often found at an inclusion, impurity or surface flaw, which acts as a local stress raiser resulting in small scale plastic deformation. Analysis of the fatigue life based on linear elastic fracture mechanics requires that the random nature of production, crack growth, applied load and the subsequent failure due to cracking are properly taken into account (Ge et al., 2014). A prerequisite, however, is sufficient database of input random variables.

Even though steel production and building technology (bolting and welding of connections) have developed rapidly, structures are dimensioned using known parameters, such as yield strength and ultimate strength without consideration to defects. A number of these data are now currently available (e.g. Sadowski et al., 2015). Nevertheless, the design of existing steel construction was not based explicitly on these data, thus, it is not possible to reliably determine, which parts of the bearing structures

\footnotetext{
Assoc. Prof. Ing. Martin Krejsa, Ph.D.: Department of Structural Mechanics, Faculty of Civil Engineering, VSB-Technical University of Ostrava, Ludvika Podeste 1875/17; 708 33, Ostrava - Poruba; CZ, martin.krejsa@vsb.cz

** Ing. Přemysl Pařenica: Department of Structural Mechanics, Faculty of Civil Engineering, VSB-Technical University of Ostrava, Ludvika Podeste 1875/17; 708 33, Ostrava - Poruba; CZ, premysl.parenica@vsb.cz

*** Ing. Petr Lehner: Department of Structural Mechanics, Faculty of Civil Engineering, VSB-Technical University of Ostrava, Ludvika Podeste 1875/17; 708 33, Ostrava - Poruba; CZ, petr.lehner@vsb.cz

† Assoc. Prof. Ing. Jiř́ Brožovský, Ph.D.: Department of Structural Mechanics, Faculty of Civil Engineering, VSB-Technical University of Ostrava, Ludvika Podeste 1875/17; 708 33, Ostrava - Poruba; CZ, jiri.brozovsky@vsb.cz

‡ Assoc. Prof. Ing. Vít Křivý, Ph.D.: Department of Structures, Faculty of Civil Engineering, VSB-Technical University of Ostrava, Ludvika Podeste 1875/17; 708 33, Ostrava - Poruba; CZ, vit.krivy@vsb.cz

\# Ing. Jaroslav Kozák: Design department for steel construction, Vitkovicke strojirny, Ruska 1142/30; 703 00, Ostrava Vítkovice; CZ, jaroslav.kozak@vitkovicke-strojirny.cz
} 
are designed adequately and, which on the other hand, require more attention and more frequently planed inspection (Zhang et al., 2001). However, some data cannot be determined from inspections or laboratory measurements and remain burdened with epistemic uncertainty in theoretical studies, e.g. (Kiureghian et al., 2009). Common studies of the misalignment of failure probability over time tend to focus on structural details or system (e.g. Kralik, 2017; Vican et al., 2016 and Kala, 2015), however, a comprehensive probabilistic methodology generally applicable to bridge structures is currently missing.

Numerical methods, mostly based on the finite element method (FEM), have been developed to aid in the understanding of the behaviour of the fatigue phenomena. A probabilistic FEM approach is proposed to evaluate the time-dependent fatigue reliability levels of steel bridge details (Guo et al., 2012).

The analysis of the steel truss structure supporting the crane track is based on the methodology published in (Krejsa et al., 2017 and Seitl et al., 2017). It was necessary to create a complex static 3D model with a moving load. Variable crane loading and load amplitude were obtained from probability analysis and were converted to the amplitude spectrum of static magnitudes. Among other method, the Rain Flow method was used. The final spectrum was used to define load for the numerical models of elements and connections. The critical parts in terms of fatigue and life expectancy are possible to identify by this approach.

\section{Methodology}

The calculation methodology is presented on the crane bridge built in 1920. The study of documentation and basic diagnostics of the entire construction was the first phase of the analysis. The preparation of the computational model of the structure was the next step, which included the determination of the details to be analyzed for fatigue. Analysis of one of this detail was third phase. Specifically it was a part of connection of supporting steel structure diagonal.

\subsection{Model of crane movement}

As mentioned above, the first phase was to prepare a load model simulating crane movement on the track. The numerical 3D model of the whole construction was created. The supporting steel structure under the crane was considered as a three-armed continuous beam. The selected diagonal No. B355 is in the middle of span (See Fig. 1). The selection was dependent on the assumption of searching for the greatest internal force.

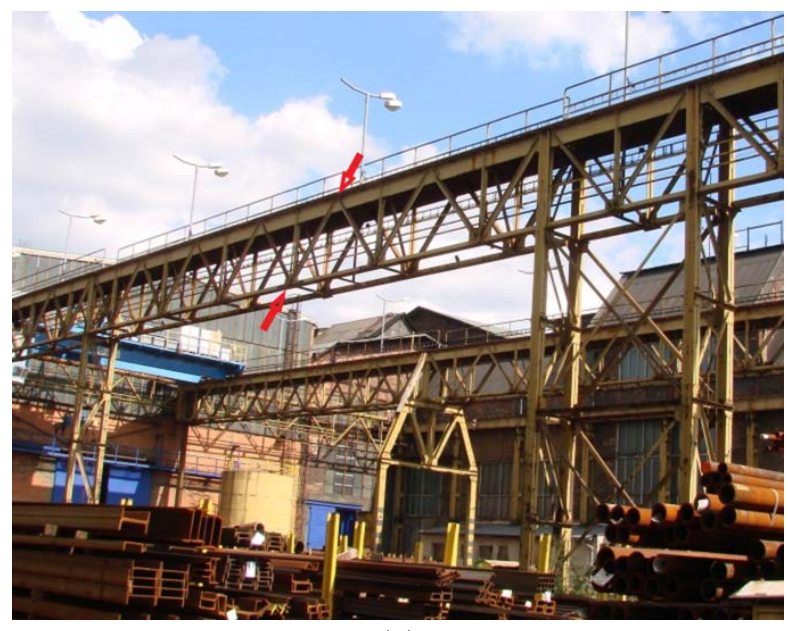

(a)

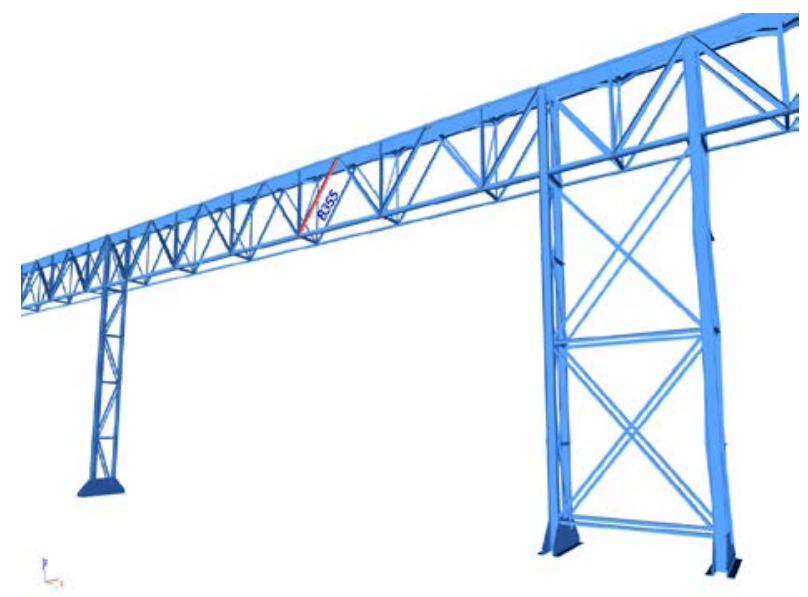

(b)

Fig. 1: Part of the supporting steel structure of the crane track. A realistic view (a) and model of construction with the marked diagonal B355 (b).

The system was considered as a truss frame from a static point of view. In the longitudinal direction it was provided with a reinforcing field and crosswise the legs are fixed as well as anchored by a pair of threaded rods. Connections of the members were modeled as interlocked. In the support of columns, reinforcement plates were modeled using shell FEM elements. The overall model in numerical software SCIA Engineer contains 9877 nodes, 2888 2D elements and 9257 1D elements. 
To determine the influence line, a pair of forces $(2 \times 50 \mathrm{kN})$ were placed along the length of the path. The location of the forces was on the top of the truss beam, on which the rails of the bridge crane are modeled. The influence line on the selected diagonal was obtained (See Fig. 2).

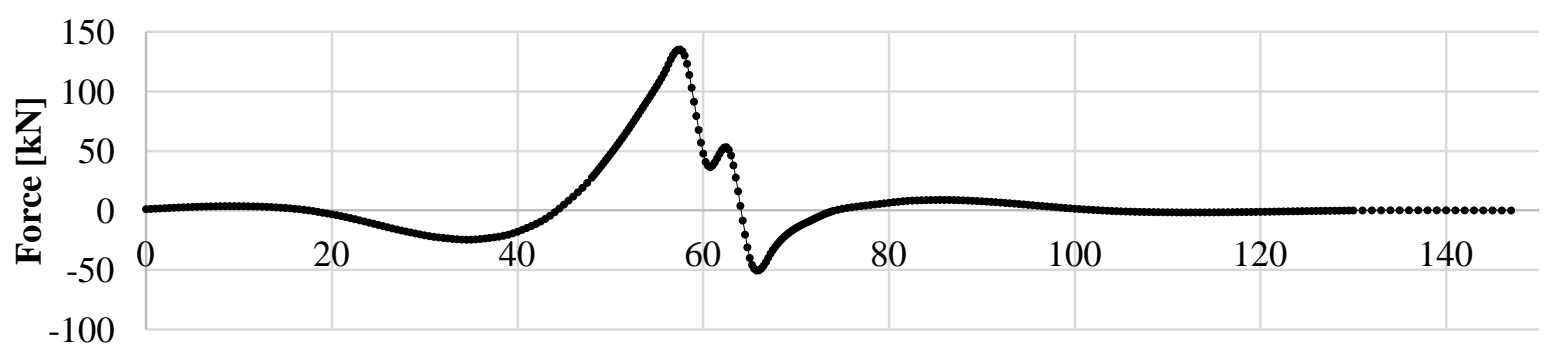

Shift path $[\mathrm{m}]$

Fig. 2: The influence line on the selected diagonal by simulation of moving load caused by bridge crane.

\subsection{Spectrum stress range}

The direct calculation of the time-dependent effect of the load is possible to obtain using the spectrum stress range. In many cases it is the only option to obtain the necessary data. The accuracy of the chosen calculation procedure depends on many input factors, which are obviously variable (e.g. weight of lifted loads, bridge crane position and position of trolley, number of crane crossing per operating cycle). The model of load had these assumptions. Each shift contained 140 work cycles. $90 \%$ of work cycles are in one day. There are three parts of load distribution: $50 \%$ of cycles were unloaded, $40 \%$ were uniform loaded from $0 \mathrm{~kg}$ to $5000 \mathrm{~kg}$ and $10 \%$ were loaded from 5,000 $\mathrm{kg}$ to $8,000 \mathrm{~kg}$. For calculating the response in the crane wheels, the actual crane weight, load weight, truck lift weight, and truck location were used.

To determine the position of the crane in each simulation a uniform distribution was used. Simulation of load history was obtained by combining reactions and influence line on selected diagonal. Fig. 3 shows the amplitude of the load variable in one shift. It is necessary to say, that one of traditional method to obtain fatigue resistance is use of the amplitude spectrum of static magnitudes on the analyzed detail.

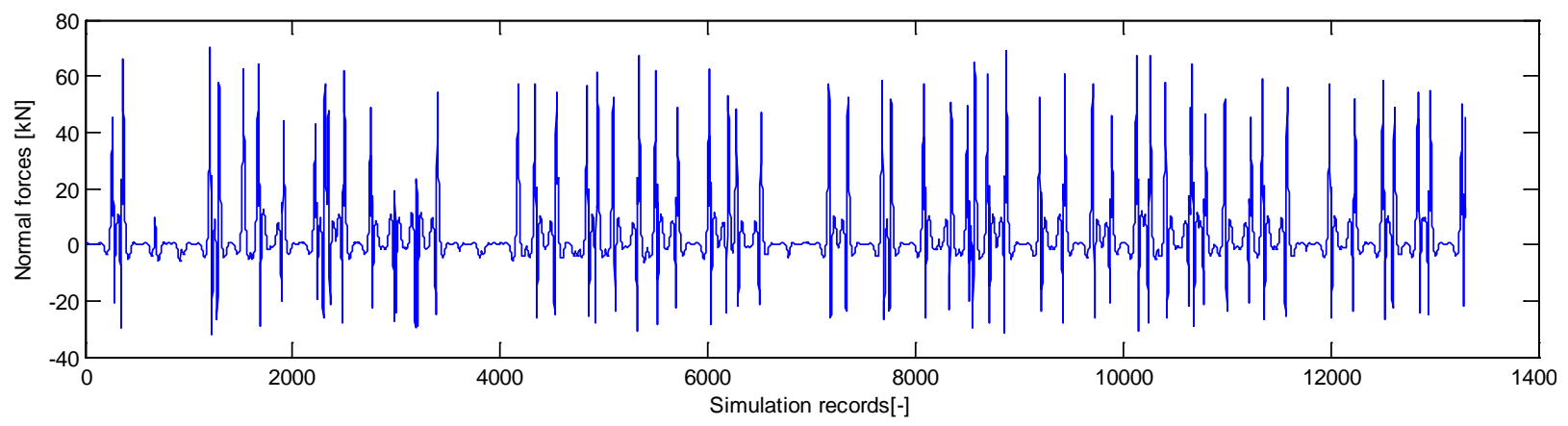

Fig. 3: Amplitude of load history data for selected diagonal from the structure at one work shift.

\subsection{Numerical model of selected connection}

The obtained spectrum stress range was used for loading of selected connection. It was a selected part of riveted connection of a diagonal. The model contains a joint plate and connecting diagonals made of 2xL90/10 with 3 rivets with a diameter of $24 \mathrm{~mm}$.

The detail is modeled by volume elements in ANSYS system, with rod elements on the diagonal forehead. The individual parts were connected to each other. Detachment of the contacts in the tension, the shear connection and pre-stressing in the rivets were not considering. Material was chosen for all parts as classic carbon steel. The considered detail and the model of connection is shown in Fig. 4. The diagonal was loaded with a normal force that was variable depending on the amplitude of load history data. 


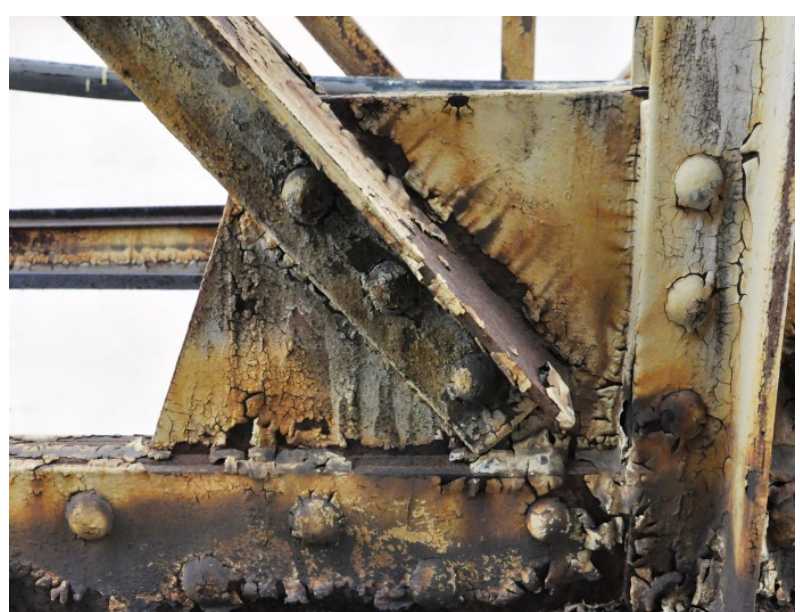

(a)

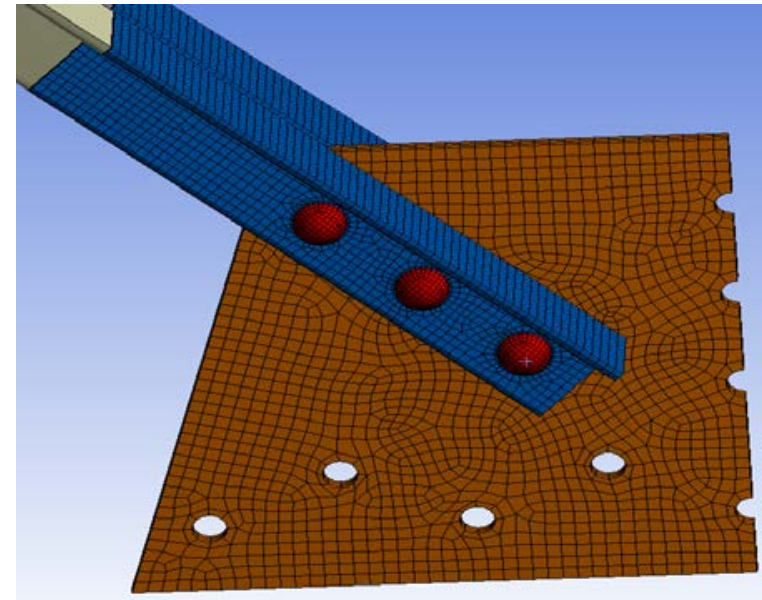

(b)

Fig. 4: Detail (a) and numerical model (b) of selected diagonal connection.

\section{Conclusions and future works}

Presented numerical model allows to obtain and analyse many results focused on fatigue, such as identifying a critical location in a joint, lifespan of a joint in years, etc. In further research, material tests will be carried out on the diagonals and rivets removed from the structure. The actual material characteristics obtained will be used with the created numerical model for a more accurate prediction of structural fatigue damage.

\section{Acknowledgement}

This contribution has been developed as a part of the research project GACR 17-01589S “Advanced computational and probabilistic modelling of steel structures taking account fatigue damage" supported by the Czech Grant Agency and also has been completed thanks to the financial support provided to VSBTechnical University of Ostrava by the Czech Ministry of Education, Youth and Sports from the budget for conceptual development of science, research and innovations for the 2018 year.

\section{References}

Ge, H. \& Kang, L. (2014) Ductile Crack Initiation and Propagation in Steel Bridge Piers Subjected to Random Cyclic Loading. Engineering Structures, 59, pp. 809-820.

Guo, T., Frangopol, D.M. \& Chen, Y. (2012) Fatigue Reliability Assessment of Steel Bridge Details Integrating Weigh- in-motion Data and Probabilistic Finite Element Analysis. Computers and Structures, 112, pp. 245-257.

Kala, Z. (2015) Sensitivity and reliability analyses of lateral-torsional buckling resistance of steel beams. Archives of Civil and Mechanical Engineering, 15, 4, pp. 1098-1107.

Kiureghian, A. \& Ditlevsen, O. (2009) Aleatory or Epistemic? Does it matter? Structural Safety, 31, 2, pp. 105-112.

Kralik, J (2017) Experimental and Numerical Analysis of the Hermetic Tightness of NPP Bubble Tower Structure. Procedia Engineering, 190, pp. 472-479.

Krejsa, M., Koubova, L., Flodr, J., Protivinsky, J. \& Nguyen, Q.T. (2017) Probabilistic prediction of fatigue damage based on linear fracture mechanics. Frattura ed Integrita Strutturale (Fracture and Structural Integrity), 11, 39, pp. 143-159.

Sadowski, A.J., Rotter, J.M., Reinke, T. \& Ummenhofer, T. (2015) Statistical Analysis of the Material Properties of Selected Structural Carbon Steels. Structural Safety, 53, pp. 26-35.

Seitl, S., Miarka, P., Kala, Z. \& Klusak, J. (2017) Effect of rivet holes on calibration curves for edge cracks under various loading types in steel bridge structure. Procedia Structural Integrity, 5, pp. 697-704.

Vican, J., Gocal, J., Odrobinak, J. \& Kotes, P. (2016) Analysis of existing steel railway bridges. Procedia Engineering, 156, pp. 507-514.

Xiang, Y. \& Liu, Y. (2011) Application of Inverse First-order Reliability Method for Probabilistic Fatigue Life Prediction. Probabilistic Engineering Mechanics, 26, 2, pp. 148-156.

Ye, X. W., Su, Y. H. \& Han, J. P. (2014) A State-of-the-Art Review on Fatigue Life Assessment of Steel Bridges. Mathematical Problems in Engineering, 2014, pp. 1-13.

Zhang, R., Mahadevan, S. (2001), Fatigue Reliability Analysis Using Nondestructive Inspection. Journal of Structural Engineering-ASCE, 127, 8, pp. 957-965. 